\section{Financiamento público da saúde pelo governo do Estado do Paraná, Brasil, 1991-2006}

\author{
Public health financing by the Paraná State \\ Government, Brazil, 1991-2006
}

\footnotetext{
${ }_{1}^{1}$ Departamento de Enfermagem, Universidade Estadual do Oeste do Paraná, Cascavel, Brasil.

2 Departamento de

Economia, Faculdade

Estadual de Ciências

Econômicas, Apucarana,

Brasil.

3 Hospital Universitário

de Londrina, Universidade

Estadual de Londrina

Londrina, Brasil.

4 Centro de Ciências da

Saúde, Universidade

Estadual de Londrina,

Londrina, Brasil.

Correspondência

L. Cordoni Jr.

Departamento de Saúde

Coletiva, Centro de Ciências

da Saúde, Universidade

Estadual de Londrina.

Rua Nevada 615, Londrina,

PR 86060-300, Brasil.

cordoni@sercomtel.com.br
}

\section{Abstract}

This study discusses public health financing by the State Government of Paraná, Brazil. Expenditures by the State Health Department were analyzed as a proxy for health expenditures by the State Government of Paraná from 1991 to 2006. Three criteria were used: (1) expenditures as a percentage of net revenue, in accordance with Constitutional Amendment no. 29; (2) expenditures as a percentage of total budget outlay; and (3) per capita health expenditures with the State's own resources. The findings showed distinct trends in expenditures during the period studied, the most recent being an expansion in spending of funds from the State treasury.

Health Economics; Health Public Policy; Health Financing
Manoela de Carvalho 1

Aylton Paulus Júnior 2,3

Luiz Cordoni Jr. 4

\section{Introdução}

As propostas desenvolvidas pelo Movimento da Reforma Sanitária Brasileira, tais como universalização, descentralização, hierarquização dos serviços e controle social foram formalizadas na VIII Conferência Nacional de Saúde em 1986, e incorporadas à Constituição Federal de 1988, como princípios e diretrizes do Sistema Único de Saúde (SUS) 1,2. A Constituição, apesar de garantir a saúde como direito universal e dever do Estado, não detalhou a forma como isto se daria, nem deixou claro o montante de recursos que deveria ser destinado a este setor, transferindo tais decisões para leis complementares.

Na primeira Lei que regulamenta o funcionamento do SUS (Lei Federal $n^{\circ}$. 8080, de 19 de setembro de 1990) 3 os artigos referentes ao financiamento mereceram veto presidencial, o que provocou forte reação de setores da sociedade e resultou na aprovação de uma segunda Lei Orgânica da Saúde 4 (Lei Federal no. 8142, de dezembro de 1990) ${ }^{5}$. Esta dispôs sobre a participação da comunidade na gestão do SUS e sobre as transferências de recursos financeiros entre esferas de governos ${ }^{5}$. Trata-se do primeiro diploma legal a abordar assunto de natureza financeira relativo à saúde. Entretanto, não definiu os montantes de recursos a serem destinados ao setor nas três esferas de governo, o que só veio ocorrer com a promulgação da Emenda Constitucional $n^{\circ} .296$. Em 1993 é criado o Sistema de Informações so- 
bre Orçamentos Públicos em Saúde (SIOPS) 7 que passa a disponibilizar na Internet, a partir de 2000, informações sobre as execuções orçamentárias referentes às ações e serviços de saúde dos municípios, estados, Distrito Federal e União, tornando possível o acompanhamento sistemático dessas execuções.

A Norma Operacional de Assistência à Saúde (NOAS 01/2001) 8 determina que a informação ao SIOPS seja requisito para habilitação de estados e municípios às condições de gestão previstas na Norma. Também a Lei de Responsabilidade Fiscal 9, a partir de 2002, estabelece o SIOPS como fonte para coleta das informações solicitadas no demonstrativo da saúde que integra o relatório resumido da execução orçamentária da Lei de Responsabilidade Fiscal. As ações e regulamentações acima demonstram a importância crescente do campo da Economia da Saúde e a necessidade de estudos no interior desse campo. De fato, estes vêm se expandindo na América Latina 10.

No Brasil, tais estudos têm enfocado principalmente os aspectos macroeconômicos como os que mensuram a evolução do gasto federal e/ou comparam os gastos federais, regionais, estaduais e municipais no âmbito do país como um todo 11. Quando se trata de análise de um determinado estado, as pesquisas são quase inexistentes. Os autores identificaram um único trabalho sobre o financiamento público da saúde pelo governo paranaense, elaborado por Cordoni Jr. 12 que pesquisou as despesas realizadas em saúde comparativamente às receitas e despesas do Tesouro do Estado entre 1976-1984. Assim, o presente trabalho tem por objetivo analisar o comportamento dos gastos com saúde do Governo do Paraná, Brasil, no período de 1991-2006.

\section{Metodologia}

No presente trabalho não foi possível utilizar os dados do SIOPS porque os mesmos estão disponíveis somente após 2000, formando série histórica de curta duração, não permitindo uma completa análise de tendência. Assim, foram analisadas as despesas totais da Secretaria de Estado da Saúde do Paraná (SESA), ano a ano, no período de 1991-2006. Foi realizada análise documental, considerando-se apenas as despesas com recursos do Tesouro do Estado. As fontes de informação foram os Balanços Gerais do Estado, documentos de prestações de contas produzidos anualmente pela Secretaria de Estado da Fazenda e encaminhados ao Poder Legislativo. Contém os elementos contábeis das gestões orçamentária, financeira e patrimonial, relativos às administrações direta e indireta do exercício findo (ano anterior). Estes documentos não são publicados, mas ficam disponíveis para consulta na Secretaria de Estado da Fazenda do Paraná.

As despesas em ações e serviços de saúde executadas por outros órgãos do Governo Estadual, tais como as Secretarias de Estado de Ciência, Tecnologia e Ensino Superior, da Segurança Pública e da Justiça e Cidadania não puderam ser analisadas devido ao baixo grau de desagregação dos dados das fontes utilizadas. Esta é uma limitação do presente estudo. Entretanto, estima-se que os gastos em saúde nesses órgãos são proporcionalmente pequenos frente aos gastos da SESA. Desta forma, a série de despesas registradas como da Secretaria de Estado da Saúde é indicadora (proxy) do total de recursos destinados à saúde. A evolução da execução orçamentária da SESA foi comparada à "receita vinculável" prevista na Emenda Constitucional $n^{\circ} .296$.

Como a Emenda Constitucional $n^{o} .29^{6}$ prevê a vinculação de percentuais da receita para aplicação em saúde, há que se definir à qual parte do orçamento do estado serão vinculados tais percentuais, pois o orçamento conta com recursos próprios mais as transferências intergovernamentais da união para os estados, menos as transferências dos estados para os municípios. Assim, para interpretar a "base vinculável" o Conselho Nacional de Saúde instituiu um grupo técnico interinstitucional que produziu os "Parâmetros Consensuais Sobre a Implementação e Regulamentação da Emenda Constitucional 29" 13. Neste documento "entende-se como base vinculável a receita dos entes federativos que estará sujeita à vinculação de recursos para aplicação exclusiva em ações e serviços de saúde. É composta por impostos próprios e transferidos, dos quais são deduzidas as transferências constitucionais intergovernamentais" 13. No presente trabalho, para a comparação do percentual gasto durante o período estudado, foram utilizadas as recomendações do citado documento do Conselho Nacional de Saúde 13. A Figura 1 mostra a composição da receita vinculável por este critério.

Em complemento ao estudo das despesas da SESA comparado com a receita vinculada pelo conceito da Emenda Constitucional $n^{\circ}$. 29, o trabalho também aborda a análise da despesa da SESA em relação às despesas totais do estado, bem como avalia a série que mostra a evolução dos gastos per capita.

O estudo dos dinheiros aplicados na SESA por habitante do Estado do Paraná requereu, para fins de comparabilidade, ajuste que descontou a inflação. Para tanto as despesas da SESA foram deflacionadas pelo índice geral de preços da Fundação Getúlio Vargas, tendo por base o mês de abril de 200714. 


\section{(+) Receitas de impostos estaduais:}

ICMS: imposto sobre operações relativas à circulação de mercadorias e prestação de serviços de transporte interestadual e de comunicação

IPVA: imposto sobre a propriedade de veículos automotores

ITCMD: imposto sobre transmissão "causa mortis" e doação de bens e direitos

(+) Receitas de impostos transferidos pela União:

FPE: fundo de participação dos estados e do Distrito Federal;

IRRF: imposto de renda retido na fonte

IPI exportação: imposto sobre produtos industrializados

ICMS exportação (Lei Kandir): Lei Complementar n. 87/96

(+) Receita de dívida ativa tributária de impostos

(-) Transferências financeiras constitucionais e legais a municípios:

ICMS: imposto sobre operações relativas à circulação de mercadorias e prestação de serviços (25\%)

IPVA: imposto sobre a propriedade de veículos automotores $(50 \%)$

IPI exportação: imposto sobre produtos industrializados (25\%)

ICMS exportação (Lei Kandir): Lei Complementar n. $87 / 96$ (25\%)

Fonte: Conselho Nacional de Saúde, Ministério da Saúde 13.

A evolução das despesas da SESA, sob os três enfoques abordados, foi submetida à avaliação de um modelo linear pelo método dos mínimos quadrados buscando a identificação da linha de tendência no período estudado. O valor do parâmetro $\beta$ (coeficiente angular) foi usado para indicar as tendências.

\section{Resultados}

As Figuras 2, 3 e 4 apresentam as dimensões numéricas das despesas com saúde no Estado do Paraná no período de 1991-2006 por três critérios: (a) evolução das despesas com ações e serviços de saúde comparada com a receita vinculável; (b) evolução das despesas com ações e serviços de saúde comparada à execução orçamentária e; (c) evolução das despesas com ações e serviços de saúde per capita.
Evolução das despesas com ações e serviços de saúde comparada com a receita vinculável do Estado do Paraná, 1991-2006

Este tópico evidencia a parte da receita vinculável correspondente ao orçamento executado da SESA. No conceito da Emenda Constitucional $n^{o}$. 29 as despesas com saúde deveriam alcançar $7 \%$ em 2000 evoluindo para $12 \%$ a partir de 2004 .

A relação resultante da comparação da despesa contabilizada para a SESA com a receita vinculável do Estado do Paraná, em termos percentuais, não apresenta tendência dominante no período de análise ( $\beta$ próximo de zero) conforme ilustra a Figura 2. Os percentuais da despesa realizada pela SESA em relação à receita vinculada não apresentam bom ajuste linear por conter estruturas quebradas de tendências. Observe-se a série histórica mostrando efeitos da Emenda Constitucional $n^{o} .29$ invertendo a tendência declinante iniciada em 1998. Ademais, observa-se ainda que a tendência geral não é permanente dado que os efeitos da emenda apenas iniciam a partir de 2000. Dessa forma, a série dos dados de 1991-2006, enquanto conjunto, carece de cui- 
Figura 2

Porcentagem da despesa da Secretaria de Estado da Saúde do Paraná, Brasil, em relação à receita vinculada e linhas de tendência.

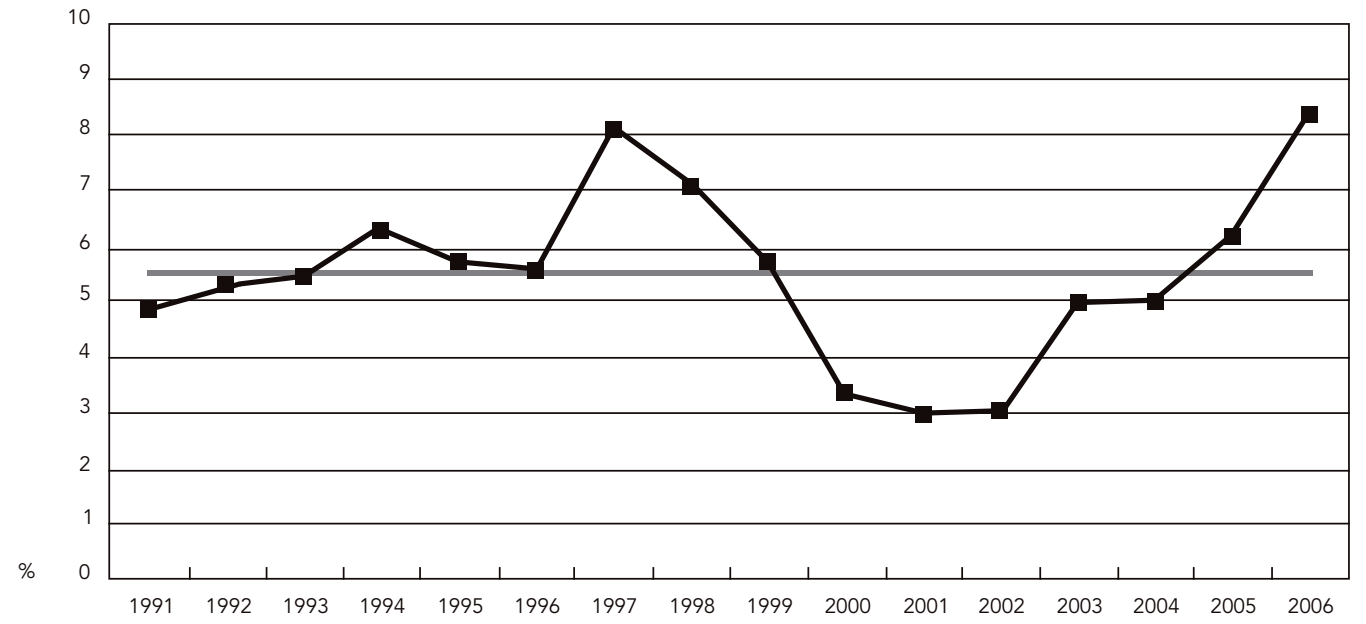

Figura 3

Porcentagem da despesa da Secretaria de Estado da Saúde do Paraná, Brasil, em relação à despesa total do estado.

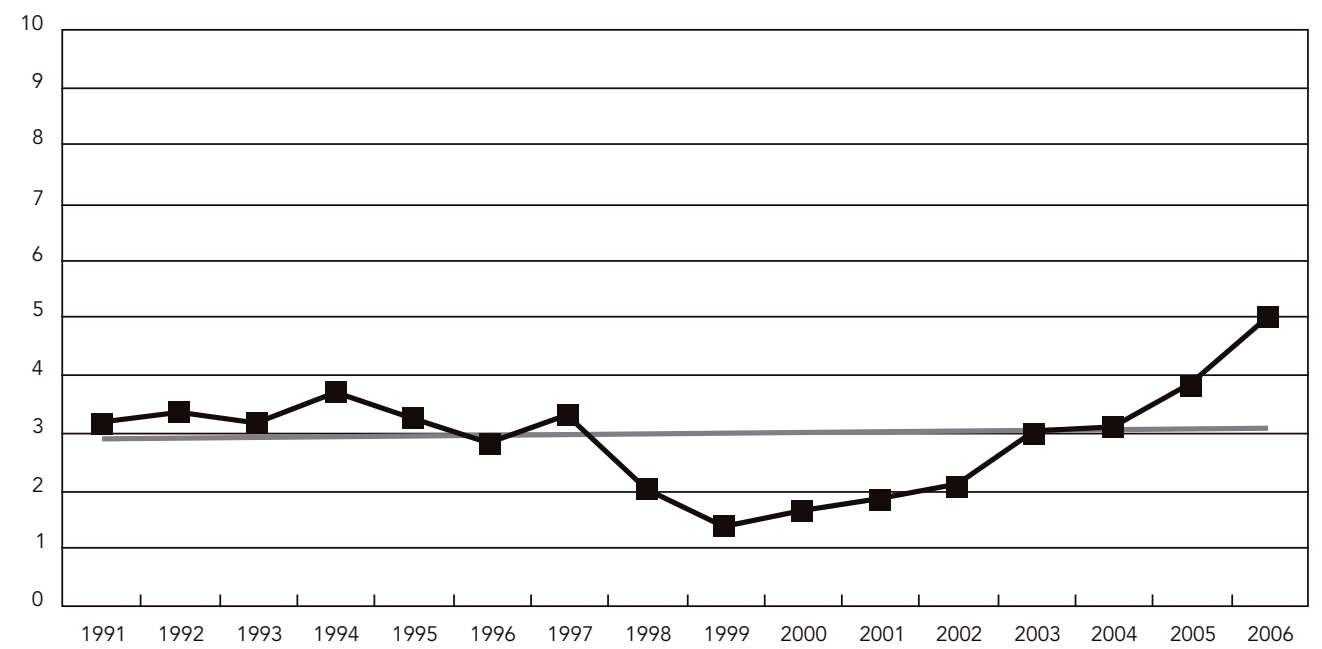




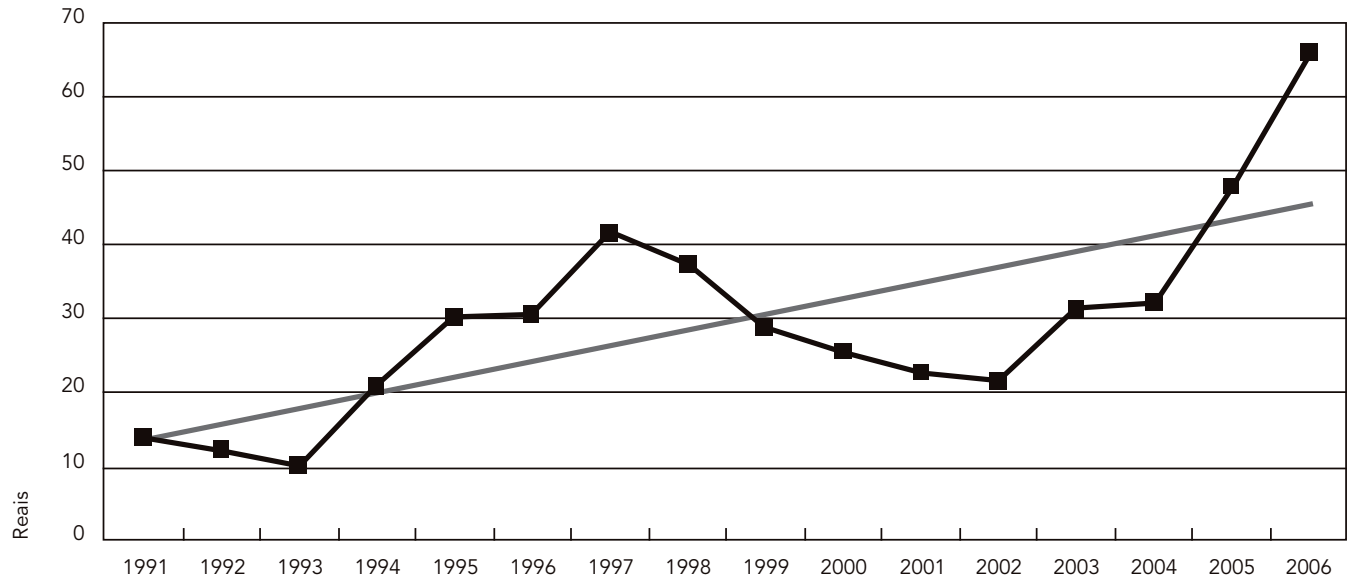

dados para inferências. Entretanto, é trivial a observação da existência de períodos distintos de dados tais como os de 1991-1997; 1998-2001; e 2002-2006.

A Figura 2 ilustra a tendência geral neutra das despesas da SESA em relação à receita vinculada do estado no período de 1991 a 2006. Entretanto, destaca-se que o período de orçamentos decrescentes foi o de 1998-2001. O menor percentual da série foi evidenciado para o ano de 2001 e o maior em 2006

\section{Evolução das despesas com ações e} serviços de saúde comparada à execução orçamentária do Estado do Paraná, 1991-2006

A análise por este segundo critério mostra qual é a parte das despesas da SESA em relação ao orçamento executado do Estado do Paraná, avaliadas na perspetiva do uso de recursos próprios do estado.

O ajuste da série de 1991-2006 que mostra o percentual das despesas da SESA em relação às despesas totais do Estado do Paraná, considerando somente recursos próprios, também não apresenta tendência dominante ( $\beta$ próximo de zero). Nota-se uma tendência estável para o período de 1991-1997 com importante diminuição relativa de recursos nos anos de 1998-1999.

Observe-se que os dados de 2000 e os dos anos seguintes indicam tendência ascendente refletindo as discussões e a possível implementação da Emenda Constitucional $n^{o}$. 29. O ano de 2006 foi o de maior participação da SESA no orçamento do estado e o ano de 1999 foi o de participação mais baixa. A Figura 3 mostra esta situação.

\section{Evolução das despesas com ações e serviços de saúde per capita do Estado do Paraná, 1991-2006}

Esta terceira abordagem da apresentação mostra as despesas da SESA em valores atualizados para abril de 2007 por habitante do Estado do Paraná. É o conceito da despesa per capita.

O resultado encontrado quando se considera a população do Estado do Paraná apresenta a tendência geral crescente das despesas com saúde per capita para o período de 1991-2006 ( $\beta=2,100362)$. Ocorre que o crescimento real das despesas foi superior ao crescimento da população do Estado do Paraná no período de análise, o que resultou em mais dinheiro aplicado na SESA, por habitante, como ilustra a Figura 4.

Observe-se que a estrutura de dados da série temporal também é quebrada. De 1998-2001 as despesas per capita assumem tendência declinante indicando, pelo critério adotado, uma menor atenção à saúde neste período. Entretanto, a partir de 2002 ocorre inversão da série refletindo o esforço da Emenda Constitucional $n^{\circ} .29$ na busca de mais recursos para a saúde. O menor valor encontrado ocorreu em 1994 e a melhor relação em 2006. A Figura 4 ilustra o crescimento dos dados até 1997, o declínio iniciado em 1998 e a recuperação a partir de 2003. 


\section{Discussão}

O processo de descentralização ocorrido nas políticas de saúde, a partir da década de 90 , foi acompanhado por obstáculos em relação ao financiamento das ações e serviços de saúde, amenizados a partir dos anos 2000 com a aprovação da Emenda Constitucional $n^{\circ}$. 29. No entanto, os entraves na regulamentação desta emenda, detalhados por Faveret 15, e os embates com a área econômica, como alertam Marques \& Mendes 16, dificultaram sua real implementação, especialmente nos âmbitos estaduais. O quanto de recursos os estados devem aplicar em saúde foi resolvido legalmente, mas de fato há grande resistência de governadores em aplicar o percentual definido haja vista que o total de estados que cumpriram a Emenda Constitucional ${ }^{\circ}$. 29 foi de 59\% em 2000, $33 \%$ em 2001, 41\% em 2002 e 52\% em 200317. Segundo a Nota Técnica $n^{\circ}$. 08/2007 18 da Secretaria Executiva do Ministério da Saúde, apenas 7, dos 27 estados, cumpriram os mínimos legais em 2005. Observe-se que o aumento de recursos aplicados pode ser condição para melhorar a saúde sem, entretanto, termos a garantia deste resultado. Existem casos onde o maior gasto teve pouco ou nenhum impacto 19. O aumento dos gastos para uma mesma população implica refinamentos dos diagnósticos e a utilização do progresso tecnológico. A disponibilidade de mais recursos é conveniente até o limite do exagero e ruim além deste. Algumas práticas na saúde precisam ser mudadas como as cesárias e outros procedimentos excessivos e nem sempre necessários 20 .

$\mathrm{O}$ quanto uma nação precisa aplicar em saúde tem sido objeto de estudos que em geral usam parâmetros relativos de renda. A referência encontrada para os países da América Latina e Caribe em estudo com dados dos anos 90 é a de que quanto maior a renda per capita, maior é o gasto per capita com saúde 21 . O mesmo estudo evidenciou que o Brasil, Argentina, Uruguai e Colômbia aplicaram em saúde valores acima da média esperada para suas respectivas rendas per capita. Além disso, em um país como o Brasil, que apresenta grandes discrepâncias regionais em relação às condições sócio-econômicas de sua população, a distribuição eqüitativa de recursos a serem aplicados no setor social tem sido alvo de debates, estudos 22 e até mesmo alterações na legislação tributária, desde a década de 60 , como aponta Lima 23 , na tentativa de solucionar essas desigualdades não apenas geográficas.

O financiamento do gasto em saúde decorre de fontes diversas que vão da compra direta dos serviços até os impostos e as contribuições especiais. No Brasil, o financiamento das políticas públicas de saúde ocorre com recursos dos três ní- veis de governo. Na avaliação de Ugá \& Santos 24, a participação do gasto público com saúde é baixa para um sistema que assume os princípios da universalidade e da integralidade da atenção à saúde. Em 1988 foi eliminada a modalidade de seguro vinculado à carteira de trabalho assinada (critério do antigo INAMPS - Instituto Nacional de Assistência Médica e de Previdência Social) e foi definida a opção pelo financiamento usando fundos federais, estaduais e municipais, que hoje são regulados nos termos da Emenda Constitucional $n^{o}$. 29. Para os estados foi fixado cumprir, no período de 2000-2004, o índice progressivo de $7 \%$ a $12 \%$ das receitas tributárias líquidas como dinheiro de aplicação obrigatória em saúde.

As notas técnicas do SIOPS 10/2004 25 e 09/2005 26 mostraram que os recursos para a saúde aumentaram no Brasil após a implementação da Emenda Constitucional no. 29. De 2000 para 2003 os recursos públicos passaram de 3,09\% para $3,45 \%$ do Produto Interno Bruto (PIB).

Em outro documento 27 o Ministério da Saúde divulgou números, em bilhões de Reais, que sugerem o aumento da execução orçamentária ocorrida após a Emenda Constitucional $n^{\circ} .29$. Entretanto, o mesmo texto alerta que os valores são de 10 a 15 vezes menores em relação a países como o Canadá, Austrália ou Reino Unido. Alerta também que as três esferas de governo passaram a registrar como gastos em saúde despesas que não são próprias do setor ${ }^{27}$. De qualquer forma, os dados referidos no documento mostram os orçamentos executados de 2000-2005, em valores deflacionados, apresentando tendência crescente. Conclui pelo aumento real de recursos contabilizados como de saúde nas três esferas de governo.

A Legislação Constitucional propõe o patamar mínimo de aplicação em saúde relativamente à receita vinculável de 7\% para o ano 2000. Entende-se que o legislador concebeu ser este o mínimo admissível. No Estado do Paraná, se considerarmos as despesas da SESA em relação à receita vinculada no conceito da Emenda Constitucional $n^{\circ} 29$, somente nos anos de 1997 e 1998 houve superação da marca de $7 \%$, coincidindo com a aprovação do Imposto Provisório sobre Movimentação Financeira (IPMF), posteriormente transformado na Contribuição Provisória sobre Movimentação Financeira (CPMF), com vigência até 2007. Para todos os demais anos, e especialmente para os anos em que já estava em vigor a Emenda Constitucional $n^{\circ} .29$, os percentuais ficaram aquém das determinações legais tanto medidos em termos de despesas da SESA como em termos dos percentuais divulgados pelo SIOPS. 
A Resolução $n^{o} .32213$ do Conselho Nacional de Saúde reconhece o SIOPS como um instrumento fundamental no acompanhamento da vinculação constitucional de recursos da União, estados, Distrito Federal e municípios aos gastos com ações e serviços públicos de saúde. A NOAS 01/2001 8 determina que a informação ao SIOPS seja requisito para habilitação de estados e municípios às condições de gestão previstas na norma. Também a Lei de Responsabilidade Fiscal, a partir de 2002, estabelece o SIOPS como fonte para coleta das informações solicitadas no demonstrativo da saúde que integra o relatório resumido da execução orçamentária da Lei de Responsabilidade Fiscal 9.

O SIOPS passou a divulgar os valores gastos com ações e serviços de saúde (incluindo gastos em outros órgãos que não da SESA) a partir de 2000. A Nota Técnica $n^{\circ}$. 10/2004 do Ministério da Saúde 25 informa que o percentual gasto com a totalidade de ações e serviços de saúde em relação aos gastos do Estado do Paraná foram 2,4\%; $3,7 \%$ e $4,52 \%$ para os anos 2000, 2001 e 2002 respectivamente. Para 2003, o gasto apurado foi de $6,35 \% 26$ para 2004 foi de $5,44 \% 28$ e para 2005 registrou-se o percentual de $8,86 \% 29$. O conjunto dos dados apurados pela metodologia do SIOPS corrobora a tendência de elevação dos gastos com saúde a partir de 2000. Embora se trate de seqüência de apenas seis anos, os resultados reforçam a possibilidade de confirmação do efeito positivo da Emenda Constitucional $n^{\circ}$. 29. Há que se considerar também que a Norma Operacional Básica do SUS (NOB-96) e a NOAS podem ter ajudado a resgatar o papel de gestor das esferas estaduais de governo, como lembram Ugá \& Santos 30 , apontando que em 2002 os estados assumiam $20 \%$ do gasto público em saúde, ao passo que em 1993 era apenas $12 \%$. Porto 31 também observou que no período de 2000-2004 houve aumento da participação dos governos estaduais no financiamento do SUS. Porém, de qualquer forma, a previsão legal quanto ao montante dos recursos a ser aplicado não foi alcançada.

Em resposta ao não cumprimento da Emenda Constitucional $n^{o}$. 29 pelo Governo do Estado do Paraná, o movimento de controle social do SUS do estado, representado por entidades populares que compõem o Fórum Popular de Saúde do Paraná (FOPS), em agosto de 2002, protocolou uma representação junto ao Ministério Público Estadual visando à responsabilização do governo frente à inconstitucionalidade no cumprimento da Emenda Constitucional $n^{o}$. 29. Essa iniciativa resultou no ingresso pelo Ministério Público de uma ação civil pública cobrando o ressarcimento dos valores orçamentários não aplicados em ações e serviços de saúde nesse período, no valor total de R\$ 676.274.666,00 32.

A Resolução no. 01/2006 28 do Conselho Estadual de Saúde do Paraná reafirma a dificuldade evidenciada em períodos anteriores sobre o não cumprimento da Emenda Constitucional $n^{\circ}$. 29, pois repudia a aplicação de apenas $5,44 \%$ de recursos próprios em ações e serviços de saúde no ano de 2004.

A análise das séries temporais apresentadas nas Figuras 2, 3 e 4 indica que entre 1991-2006 ocorreram pelo menos três subconjuntos de dados indicativos do comportamento dos gastos com saúde no Estado do Paraná. Os períodos e tendências por critério de análise das séries temporais foram :

- SESA comparada com a receita vinculável: 1991-1997 (crescente), 1998-2001 (decrescente) e 2002-2006 (crescente);

- SESA comparada com a execução orçamentária: 1991-1997 (quase ausência de inclinação), 1998-1999 (decrescente) e 2000-2006 (crescente);

- SESA comparada com a população do estado: 1991-1997 (crescente), 1998-2002 (decrescente) e 2003-2006 (crescente).

Os dados, resumidos pelos três critérios apresentados acima, apontam que em 1998 ocorreu uma indesejável mudança de tendência sob o aspecto da quantidade de recursos aplicados em saúde, apesar da criação da CPMF neste período, e do Paraná ter sido um dos cinco estados que receberam maior percentual transferido pela instância federal, como citou o jornalista Paulo Henrique Amorim em seu site de notícias 33. A tendência decrescente permanece até os primeiros prováveis efeitos da Emenda Constitucional $n^{o} .29$ a partir do ano de 2000. Observe-se ainda que neste período (1998-2000) o coeficiente de mortalidade infantil do Paraná interrompeu a sua tendência de queda, voltando a diminuir a partir de 2001, o que sugere uma possível relação a ser investigada 34 .

Os dados divulgados pelo SIOPS 35 confirmam os resultados encontrados neste trabalho no que se refere à elevação dos gastos com saúde a partir de 2000 .

Finalmente, tais valores aplicados em saúde no Estado do Paraná estão muito distantes daqueles preconizados pelas cinco Conferências Estaduais de Saúde havidas no estado de 19912002 como evidenciou Carvalho 32. Todas elas indicaram como percentual aceitável $10 \%$ do orçamento do estado. 


\section{Resumo}

O trabalho tratou do financiamento da saúde pública pelo Governo do Estado do Paraná, Brasil. Foram examinados os gastos da Secretaria de Estado da Saúde como proxy das despesas com saúde do Governo do Estado do Paraná no período de 1991 a 2006. Foram utilizados três critérios: (1) porcentagem dos gastos em relação à receita líquida vinculável conforme Emenda Constitucional $\mathrm{n}^{\circ}$. 29; (2) porcentagem dos gastos em relação ao orçamento executado e (3) despesas per capita com saúde com recursos próprios. O resultado mostrou que no período ocorreram tendências distintas de gastos com saúde sendo a mais recente a da ampliação dos gastos com recursos do Tesouro do Estado.

Economia da Saúde; Políticas Públicas de Saúde; Financiamento em Saúde

\section{Referências}

1. Mendes EV. Distrito sanitário: o processo social de mudanças nas práticas sanitárias do Sistema Único de Saúde. 2a Ed. São Paulo: Editora Hucitec/Rio de Janeiro: ABRASCO; 1994.

2. Carvalho BG, Martin GB, Cordoni Jr. L. A organização do sistema de saúde no Brasil. In: Andrade SM, Soares DA, Cordoni Jr. L, organizadores. Bases da saúde coletiva. Londrina: Editora da Universidade Estadual de Londrina; 2001. p. 27-53.

3. Brasil. Lei Federal $n^{\circ}$. 8080, de 19 de setembro de 1990. Dispõe sobre as condições para a promoção, proteção e recuperação da saúde, a organização e o funcionamento dos serviços correspondentes e dá outras providências. http://www.planalto. gov.br/CCIVIL/Leis/L8080.htm (acessado em 05/ Abr/2006).

4. Gerschman S. Sobre a formulação de políticas sociais. In: Teixeira SMF, organizadora. Reforma sanitária em busca de uma teoria. São Paulo: Cortez Editora; 1995. p. 119-38.

\section{Colaboradores}

M. Carvalho participou da concepção do estudo, coleta e análise dos dados. A. Paulus Júnior colaborou na concepção do estudo, coleta, atualização e análise dos dados, redação e revisão do manuscrito. L. Cordoni Jr. contribuiu na concepção do estudo, na concepção do formato do artigo, na análise dos dados, na redação e na revisão do manuscrito.

\section{Agradecimentos}

Os autores agradecem as críticas e sugestões oferecidas pelo Dr. Gilson Carvalho.
5. Brasil. Lei Federal $n^{\circ}$. 8142, de 29 de dezembro de 1990. Dispõe sobre a participação da comunidade na gestão do Sistema Único de Saúde - SUS e sobre as transferências intergovernamentais de recursos financeiros na área de saúde e dá outras providências. http://www.conselhodesaude. poars.nom.br/default.php?p_secao=18 (acessado em 05/Abr/2006).

6. Brasil. Emenda Constitucional $n^{\circ} .29$, de 13 de setembro de 2000. Altera os artigos 34, 35, 156, 160 , 167 e 198 da Constituição Federal e acrescenta artigo ao Ato das Disposições Constitucionais Transitórias, para assegurar os recursos mínimos para o financiamento das ações e serviços públicos de saúde. http://www.presidencia.gov.br/ccivil/ constituicao/emc/emc29.htm (acessado em 05/ Abr/2006).

7. Ministério da Saúde. O que é o SIOPS? http://siops. datasus.gov.br/siops.php?esc $=1$ (acessado em 22/ Fev/2006). 
8. Ministério da Saúde. Portaria no ${ }^{\circ}$. 95, de 26 de janeiro de 2001. Norma operacional da assistência à saúde - NOAS-SUS 01/2001. http://www. sespa.pa.gov.br/Sus/Legisla\%C3\%A7\%C3\%A3o/ NOAS01_PT95.htm (acessado em 11/Mai/2007).

9. Brasil. Lei Complementar $n^{\circ}$. 101, de 4 de maio de 2000. Estabelece normas de finanças públicas voltadas para a responsabilidade na gestão fiscal e dá outras providências. http://www.stn.fazenda.gov. $\mathrm{br} / \mathrm{hp} /$ downloads/lei_responsabilidade/lc101_ 2000.pdf (acessado em 11/Maio/2007).

10. Hernández Peña P, Arredondo A, Ortiz C, Rosenthal G. Avances y retos de la economía de la salud. Rev Saúde Pública 1995; 29:326-32.

11. Piola SF, Biasoto Jr. G. Financiamento do SUS nos anos 90. In: Negri B, Di Giovanni G, organizadores. Brasil: radiografia da saúde. Campinas: Editora da Universidade Estadual de Campinas; 2001. p. 219-32.

12. Cordoni Jr. L. Serviços municipais de saúde no Paraná: tendências e perspectivas [Tese de Doutorado]. São Paulo: Faculdade de Saúde Pública, Universidade de São Paulo; 1986.

13. Conselho Nacional de Saúde, Ministério da Saúde. Resolução $\mathrm{n}^{\circ}$. 322, de 8 de maio de 2003. http:// conselho.saude.gov.br/resolucoes/2003/Reso322. doc (acessado em 14/Mai/2007)

14. Índice geral de preços (FGV - base: março 2007=1,00). Suma Econômica 2007; 348:38.

15. Faveret ACSC. A vinculação constitucional de recursos para a saúde: avanços, entraves e perspectivas. Ciênc Saúde Coletiva 2003; 8:371-8.

16. Marques RM, Mendes A. SUS e seguridade social: em busca do elo perdido. Saúde Soc 2005; 14: 39-49.

17. Campelli MGR, Calvo MCM. O cumprimento da Emenda Constitucional no. 29 no Brasil. Cad Saúde Pública 2007; 23:1613-23.

18. Secretaria Executiva, Ministério da Saúde. Nota técnica no. 08/2007 -SIOPS/AESD/SE/ME. http:// siops.datasus.gov.br/Documentacao/NT08-2007. pdf (acessado em 16/Jun/2008).

19. Teixeira HV, Barbosa VG. Gasto público com saúde no Brasil: possibilidades e desafios. http://www. abres.cict.fiocruz.br/docs/9.pdf (acessado em 25/ Jan/2008).

20. Zucchi P, Del Nero C, Malik AM. Gastos em saúde: os fatores que agem na demanda e na oferta dos serviços de saúde. Saúde Soc 2000; 9:127-50.

21. Médice A. Financiamento público e privado em saúde na América latina e Caribe: uma breve análise dos anos noventa. Brasília: Departamento de Desenvolvimento Sustentável, Divisão de Desenvolvimento Social, Banco Interamericano de Desenvolvimento; 2005. (Nota Técnica de Saúde, 3/2005).

22. Porto S, Martins M, Travassos C, Viacava F. Avaliação de uma metodologia de alocação de recursos financeiros do setor saúde para aplicação no Brasil. Cad Saúde Pública 2007; 23:1393-404.

23. Lima LD. Conexões entre o federalismo fiscal e o financiamento da política de saúde no Brasil. Ciênc Saúde Coletiva 2007; 12:511-22.
24. Ugá MAD, Santos IS. Análise da equidade do financiamento do Sistema de Saúde Brasileiro. http:// portal.saude.gov.br/portal/arquivos/pdf/ciclo22006_02.pdf (acessado em 26/Jan/2008).

25. Departamento de Economia da Saúde, Secretaria de Ciência, Tecnologia e Insumos Estratégicos, Ministério da Saúde. Nota técnica no ${ }^{\circ}$ 10/2004. http://siops.datasus.gov.br/Documentacao/NT\% 20010\%20EC\%2029\%20Estados\%202000\%202002. PDF (acessado em 12/Jun/2008).

26. Departamento de Economia da Saúde, Secretaria de Ciência, Tecnologia e Insumos Estratégicos, Ministério da Saúde. Nota técnica nº 009/2005. http://siops.datasus.gov.br/Documentacao/NT \%20009\%202005\%20EC\%2029\%20Estados.pdf (acessado em 12/Jun/2008).

27. Ministério da Saúde/Organização Pan-Americana da Saúde. Painel de indicadores do SUS. Brasília: Ministério da Saúde; 2006.

28. Conselho Estadual de Saúde do Paraná. Resolução $n^{\circ}$. 01/2006. Aprovar moção de aplausos à Secretaria Executiva do CES/PR pelo dinamismo, perseverança e seriedade no trabalho, paciência nas interlocuções com os conselheiros e principalmente pela atuação na 7a Conferência Estadual de Saúde do Paraná, imprescindível para o sucesso da mesma. http://www.saude.pr.gov.br/CES/index.html (acessado em 16/Jun/2007).

29. Departamento de Economia da Saúde, Secretaria de Ciência, Tecnologia e Insumos Estratégicos, Ministério da Saúde. Nota técnica nº. 02-A/2007. http://www.conass.org.br/admin/arquivos/NT 2A_2007.pdf (acessado em 12/Jun/2008).

30. Ugá MAD, Santos IS. Uma análise da progressividade do financiamento do Sistema Único de Saúde (SUS). Cad Saúde Pública 2006; 22:1597-609.

31. Porto SM. Comentário: avanço e problemas no financiamento da saúde pública no Brasil (19672006). Rev Saúde Pública 2006; 40:576-8.

32. Carvalho M. O impacto das conferências de saúde na definição do financiamento do SUS no Paraná (1991-2002) [Dissertação de Mestrado]. Londrina: Universidade Estadual de Londrina; 2004.

33. Amorim PH. CPMF: como é a divisão. http:// conversa-afiada.ig.com.br/materias / 467501468000/467915/467915_1.html (acessado em 29/ Jan/2008).

34. Watanabe TL, Vianna RCX, Vian I. A vigilância epidemiológica dos óbitos maternos e infantis no Paraná. Boletim Epidemiológico de Curitiba 2006; 9:3.

35. Ministério da Saúde. A implantação da EC 29: apresentação dos dados do SIOPS, 2000 a 2003. http://siops.datasus.gov.br/Documentacao/ Implanta\%C3\%A7\%C3\%A3o_EC_29_dados_ SIOPS.PDF (acessado em 16/Jun/2007).

Recebido em 22/Ago/2007

Versão final reapresentada em 11/Fev/2008

Aprovado em 27/Mar/2008 